\title{
DISCUSIÓN SOBRE LA PRESENCIA DE LA BRUJERÍA EUROPEA Y DEL CHAMANISMO MAPUCHE EN UN RELATO DE MARTA BRUNET**
}

\author{
DISCUSSION ABOUT THE PRESENCE OF EUROPEAN WITCHCRAFT \\ AND MAPUCHE SHAMANISM IN A SHORT STORY BY MARTA BRUNET
}

\author{
José Manuel Rodríguez \\ Universidad de la Frontera. Temuco, Chile \\ jose.rodriguez@ufrontera.cl \\ José Quidel Lincoleo \\ Universidad Católica de Temuco. Temuco, Chile \\ quidelin@gmail.com
}

\begin{abstract}
Resumen: La bruja durante siglos fue cruelmente perseguida en Europa. Mujeres de todas las edades estuvieron acusadas de practicar las artes hechiceriles, incluso por sus más cercanos. Torturarlas, colgarlas y quemarlas eran sólo algunos de los castigos que las amenazaban. En nuestra discusión mostraremos cómo la imagen de la bruja europea contamina las características de la machi en un relato de Brunet, igualándola a la mujer que hace pactos con el demonio, sin considerar la radical diferencia. Mostraremos, además, con qué tipo de prácticas chamánicas se identifica realmente la machi del relato, además de indagar en las tensiones de género que lo recorren.
\end{abstract}

Palabras clave: Narrativa chilena, brujería europea, machi en la literatura, género y literatura, chamanismo.

\begin{abstract}
The witch was for centuries strongly chased in Europe. Women of all the ages were accused of practicing witchcraft, even for some of their closest. They were tortured, hung and burnt, and those were only some of the punishments that were threatening them. In our comment we will show how the image of the European witch contaminates the characteristics of the Machi, based on a short story by Brunet, emulating to the woman who does pact with the demon, without considering the radical

* Este artículo fue escrito en el marco del proyecto Fondecyt $\mathrm{N}^{\circ} 11110250$ "La presencia de la brujas en la narrativa latinoamericana contemporánea”. El aporte de Fondecyt fue fundamental para el desarrollo de nuestra investigación.
\end{abstract}


difference. In addition, we will show, with which type of shamanic practices the machi identifies herself, besides indagate in the tensions of genre that through it.

Keywords: Chilean narrative, European wicthcraft, Machi in literature, gender and literature, shamanism.

Recibido: 23.12.2015. Aprobado: 13.05.2016

\section{Preámbulo}

$\mathrm{D}$ URANTE MI VIDA en la Araucanía he conocido una gente notable, los mapuche. Entre ellos está el logko José Quidel. Él es profesor, antropólogo, está terminando un doctorado en Campinas y conoce profundamente la cultura de su pueblo. Un día llegó a mi oficina mientras yo leía un relato, "La machi de Hualqui" (Brunet, 1962) y empezamos a conversar sobre el chamanismo y la magia mapuche. Poco a poco me fui dando cuenta de su enorme generosidad al compartir conmigo saberes atávicos. Le pedí permiso para anotar algunas cosas y no tuvo problemas. Es importante destacar que la intención de hacerlos públicos es una intención política: mostrar cuánto tenemos que aprender de un pueblo que ha sido tan poco entendido, tan violentado, tan aplastado por la nación chilena.

El texto que sigue es un comentario crítico y funciona del siguiente modo: primero anoto unas líneas del cuento y luego interviene el profesor Quidel, quien comenta esas líneas desde los conocimientos de su cultura. Mis comentarios, también los que estén dentro de los desarrollos del logko, irán en cursiva. Creemos que así podremos desarrollar una discusión sobre las prácticas chamánicas que subyacen en el relato.

Además, intentaremos mostrar la contaminación de la imagen de la machi, que ocurre en el cuento, con elementos propios de una inquietante ficción europea, la bruja. Inquietante porque en pos de esa ficción se cometió un genocidio espantoso.

\section{La imagen de la machi}

El texto se abre con una imagen muy sugerente. Una joven se encuentra leyendo en la orilla de un plácido río cuando siente unos pasos en la orilla 
opuesta, allí anda una machi. Citamos: "La muchacha distrajo la atención del libro que leía" (256).

Profesor Quidel (Q, en adelante): evidentemente la joven proviene del mundo de la cultura y de la civilización letrada. Aquí ya se puede intuir que el texto mostrará la colisión entre dos mundos: el occidental letrado y el mundo de la "brujería" mapuche. No es menor el rasgo de que la machi esté en la orilla del frente, en la otra orilla.

Importante observación, baste recordar El arco y la lira (2006), donde Paz nos habla del "problema" que representa para el occidental la otra orilla, la presencia de la alteridad. Para hablar de la muchacha el texto necesitó dos líneas, pero con ellas, como observó José, bastó para incluirla en la civilización occidental. No son necesarias más descripciones. La joven es un arquetipo. No ocurre lo mismo con la machi, de "ellos" no sabemos nada. De ahí que el relato sienta la necesidad de entregarnos una completa descripción de la machi. Descripción que expondremos en extenso. Ahora interesa detenerse en un primer rasgo. Veamos: "La vieja avanzaba despaciosamente" (256).

Q: Lo primero que se observa es una generalización: que los machi son todas mujeres. Siempre ha habido machis de los dos sexos. Antes (se refiere a siglos pasados) había una gran cantidad de machis hombres, pero dicen que muchos de ellos empezaron a hacer "mal uso" de los conocimientos que tenían. Entraron en problemas de transgresión. Me explico: en nuestra sociedad no existe el concepto occidental de maldad en el sentido de dañar al otro. La convivencia se centra en la observancia de reglas éticas basadas, fundamentalmente, en la reciprocidad. Somos una sociedad muy respetuosa de los espacios y de los derechos del otro. Otro que incluye a las plantas, los animales, los espíritus, etc. Hay casos de trasgresiones que tienen que ver con asuntos espirituales, cuando tú agredes un ecosistema, las fuerzas que alli habitan van a generar un efecto negativo en ti. El paradigma mapuche se desarrolla a partir de la tierra, de los cerros, del espacio. Y allí adquiere significado su ser. Frente a ello los machi varones se permitieron muchas transgresiones y de allí vino la sanción social, pues los sujetos transgresivos son socialmente castigados.

Digresión: A propósito de cómo marcar el género del o la machi en la escritura, José me dice que el término no posee un género definido, al igual que muchos nombres mapuche. Machi es inclusivo, me dice. Incluye en la 
propia denominación al masculino y al femenino. La forma de marcar el género es mediante un determinante.

Q: La grave sanción social, ya aludida, se funda en el determinismo mapuche: éste enseña que venimos a cumplir una función dentro de una cadena cósmica, luego toda transgresión afecta esa cadena. Los mapuche no sólo vivimos nuestra vida, sino que también las demás vidas viven en nosotros. Formamos una cadena cósmica con los seres del mundo. Tanto con los espirituales como los materiales. De ahí que haya que tener un cuidado extremo en la convivencia con la multiplicidad de habitantes del cosmos.

Frente a lo anterior el libre albedrío asoma como una irresponsabilidad máxima que nos autoriza a hacer lo que se nos ocurra en este mundo, siempre y cuando no afecte a la única vida que otorgamos valor, la vida humana. Las demás nada valen para Occidente. Llama poderosamente la atención, además, que el pensamiento mapuche se dé en términos cosmológicos.

En otro sentido se puede mencionar una confrontación entre los modos de pensar del pueblo de José y el nuestro, pues la transgresión es positiva para el pensamiento crítico de Occidente. La filosofía comprende el carácter artificial, y artificioso, de las pesadas estructuras molares o superestructuras que define el modo de pensar y de vivir en Occidente. De ahí que fracturar sus sentidos sea positivo y una forma privilegiada de lograr esa fractura es por medio de la transgresión. Hablamos de un complejo gesto que permite desplazarse desde los sentidos dominantes marcados en la lengua. Ese desplazamiento consiste en llegar hasta los bordes de lo decible para luego superar ese mismo límite. Sólo en ese momento estaremos hablando de otro modo. En cambio, para los mapuche trasgredir es muy negativo, pues la transgresión afecta el delicado equilibrio del todo. Ellos, postulo, viven en el mundo, al contrario nuestro que "vivimos" al interior de la lengua dominante. Lengua que nos enseña a crear una realidad que nada tiene que ver con el planeta. El ejemplo mayor de la construcción de una realidad que nada tiene que ver con este bello mundo lo encontramos en la realidad virtual. Ya existen las viseras, o gafas, que se ponen sobre los ojos para no ver este mundo y sí habitar en un espacio eléctrico.

Q: Destaco que el mapuche también trasgrede lo establecido, o puede hacerlo, pero lo hace negociando con las entidades o seres encargados de mantener el equilibrio, la ética que rige el mundo (hablo de negociar, 
pues para el transgresor siempre va a existir un costo). Tales entidades son unos seres espirituales muy singulares que habitan en la cosmovisión mapuche. Estos son cuatro: los padres, una anciana y un anciano; los hermanos, una joven y un joven. Constituyen una representación simbólica de las fuerzas que establecieron la vida. Fuerzas que se desarrollan en diversos niveles, diversas dimensiones. De esas fuerzas reconocemos doce. Una, por ejemplo, es la de los astros. Hay también una fuerza, una energía que es el "newen", presente en todos los niveles y de distintas maneras. Es algo así como la vida misma, la luz es un "newen", el viento, el sol también lo son. Hablamos de asuntos materiales y espirituales, pues toda materialidad tiene un reverso de espiritualidad. De ahí que trasgredir sea algo muy delicado.

De retorno al asunto, puedo decir que otra causa de la disminución del número de machi varones fueron las guerras. En ellas cumplían rol de "pelón" (personas con capacidad de clarividencia). Los "pelones" participaban activamente de las batallas, de ahí que muchos murieran. Así empezaron a prevalecer las machis mujeres. Luego, a partir del siglo XX han reaparecido los "wenxu machi” (machi hombres). (Aquí observamos lo anunciado más arriba: el género del machi se marca con un determinante).

Un punto interesante, que se podría relacionar con el género, es lo mal comprendido que ha sido por los wingka el travestismo del machi varón. Tal transfiguración no está relacionada con la homosexualidad necesariamente. El travestismo tendría que ver con un asunto espiritual y de performance; los aliados del machi pueden ser mujeres, pero esto no lo podemos afirmar.

El aliado es esencial para el chamán, él nunca está solo en su travesía espiritual, ni tampoco en el viaje extático. Siempre debe buscar o encontrar un aliado. Ello lo muestra, por ejemplo, Carlo Ginzburg en su monumental Historia nocturna (1991).

Sigamos con el relato que describe a la machi:

alta, escueta y bien plantada desnudos los pies, ceñida entera por el chamanto que se prendía al pecho con una rodela de plata labrada. Los pelos blancos le caían por la espalda en dos trenzas peinadas a la moda indígena, sujetas por cintas rojas en que brillaban escamas metálicas (256). 
Q: La descripción cumple con el estereotipo de la india que tienen los wingka, la única corrección sería rebozo por chamanto, pues esta es una prenda propia del campesino adinerado chileno. Es una prenda masculina. El concepto "moda indígena" es de suyo discutible, no existe esa palabra, esa tan singular idea de moda entre los mapuche. Las influencias en el vestir con las cuáles cargamos son post contacto.

Asistimos a continuación a un asunto esencial que permitirá al texto contaminar a la machi. Leamos:

Pero si en la vestimenta hacía recordar a las indias, el tipo era de chilena entroncada en judíos, de los cuales heredara la nariz corvina y los ojos encajados muy adentro en las cuencas. Arrugas la surcaban íntegra. Toda la piel era de greda trizada finamente (256).

Q: La matriz judía abre la posibilidad para que la machi cumpla con un estereotipo clásico de la bruja: "nariz ganchuda". Ello junto a la descripción de las cuencas hace que la machi sea homologada a las brujas europeas. Asunto que queda claro cuando reafirma la mezcla con la etnia mapuche fijada en el color de la piel. Y si te fijas bien, no estoy inventando nada, pues la primera vez que aparece el nombre machi en el texto hay una nota a pie de página que indica "Bruja".

Este detalle, "las brujas tienen la nariz ganchuda", no es inocente, pues forma parte del arquetipo de la bruja que se construyó durante los cuatro siglos que duró la demencial y no menos criminal empresa europea de la caza de brujas (1312-1780, fechas del primer ahorcamiento y de la última quema). Bastaba que una mujer tuviese la nariz ganchuda para que demonios como Pierre de Lancre la enjuiciaran por hechicera. Juicio donde el vesánico juez, como le llama Foucault, desplegaba toda su perversión. Así, por ejemplo, acostumbraba a afeitar personalmente el vello púbico de las acusadas, pues ahí se escondían los demonios. Ello lo hacía durante la noche de tortura anterior al juicio. Luego, en el interrogatorio, las sentaba en una silla alta con las piernas abiertas para poder observar si entraba algún demonio por la vulva, finalmente mandaba a quemar o aserrar o ahogar a esa misma mujer.

Otros jueces, no tan locos como Pierre, fueron obligados por la demencia reinante a emprender juicios contra las presuntas brujas. Walter Benjamin (2015) recuerda un diálogo donde participó un jesuita alemán, 
Friederich Spee, ilustre opositor a la terrible empresa. Un amigo a quien no veía hace algún tiempo le preguntó "por qué tienes tantas canas... por la cantidad de inocentes que he visto condenar a la hoguera", fue la terrible respuesta (36).

El asunto del tiempo que duró la cacería es muy importante. Pues no sólo ocurrió durante la Edad Media, como si pertenecer a esa era exculpase a sacerdotes y jueces el quemar, ahogar, enterrar vivas a millones de mujeres, sino que durante todo el Renacimiento quemaron, lapidaron, martillaron y aserraron brujas. Mientras Leonardo pintaba la Gioconda, hombres sedientos de horror perseguían muchachas en las calles de Florencia, de París, de Rouen, de Germanía...

Sigue la descripción de la machi marcando un detalle muy singular:

Llevaba un tarro en una mano, un tarro vacío de parafina, al cual le habían puesto un asa de juncos trenzados. Y con la otra mano en la cadera caminaba lenta, fijos los ojos frente a ella en un punto único, noble en el gesto, inusitada en ese paisaje de montaña sureña, arisco y denso (257).

Q: La parafina se usaba para iluminar las noches en el campo, se vendía en tarros. La gente reutilizaba los tarros para usarlos como recipientes. No olvidar que en el siglo pasado, muchas mercancías venían en envase de lata. Luego, esta es una marca del más estricto realismo. El asa es propia de la capacidad del campesino para usar los elementos disponibles en su medio.

Es un reflejo de una ciencia menor como diría Deleuze y Guattari (1996: 234 y siguientes). Allí expone que mayor o menor no califican dos ciencias, sino dos usos o funciones de ella. Las ciencias menores consisten en desarrollar tecnologías no invasivas, que entran en relación armónica con el medio.

Ya definido el aspecto de la machi, el texto se permitirá consideraciones de otro carácter. Vamos al relato: "Era la machi de Hualqui, famosa por su leyenda de maleficios y daños" (257).

Q: Es un lugar común de los wingkas atribuir a las y los machi ser la ejecutora de maleficios y daños. Es decir, caracterizan la práctica mágica como negativa. (Y habla de la leyenda que se ha construido sobre ella. Estamos en mi oficina y José se levanta, toma el diccionario de la RAE y lee: "Leyenda: Opinión desfavorable y generalizada sobre alguien o algo, 
generalmente infundada"). Precisamente, sostiene, la atribución a la práctica de la machi cae bajo esta definición, pues los o las machi no hacen ni maleficios ni daños; la acusación del texto es infundada. Quienes están relacionados con el trabajo maligno tienen otro nombre en nuestra lengua, en nuestro mundo, ese nombre es "kalku". Los machi tienen posibilidad de trabajar con fuerzas más allá de lo terrenal, en cambio los "kalku" trabajan con fuerzas terrenales. Estos son más dados a intervenir destructivamente y reciben pago por esas intervenciones. Los machi reciben pago, pero por mejorar. Los "kalku", además, trabajan en silencio (el secreto es un elemento esencial de la brujería), de ahí su relación con la obscuridad, esta les sirve sólo para ocultarse, por ende sería difícil que un "kalku" fuese famoso entre los no mapuche. Si fuese famoso lo sería entre los mapuche y sólo sería "alguien muy nombrado", jamás entre los wingka. Menos aun cuando las relaciones entre mapuche y chilenos eran, $y$ son, tan poco fluidas.

En relación al lugar y el espacio del o la machi en la comunidad, te cuento que durante los ritos de iniciación, preparación y consagración, los o las machi se forman abiertamente frente a toda su familia y la gente de las comunidades aledañas. Así son conocidos por todos. Mientras que de un o una "kalku" nunca se sabe...

Luego, el cuento dará otras señas de la vieja. Leemos: "Vivía montaña adentro, en una casa de piedra, refugio para caminantes ahora abandonado" (257).

Q: Los mapuche viven en rucas. Esas casas de piedra eran refugios para "arrieros". También se usaron para protegerse de los chilenos cuando arrasaban con los mapuche. Es muy improbable que una machi viviese allí, a menos que fuese una exiliada. Es muy difícil que una bruja mala fuese excluida de la sociedad mapuche, pues nosotros vivimos en comunidad (esto es muy hermoso, un mapuche nunca está solo. A los viejos, por ejemplo, los cuidan entre toda la comunidad). La exclusión sólo es posible de aplicar en el caso de una falta gravísima. El exilio existe entre los mapuche. Es un castigo máximo, implica una muerte en vida, pues se pierde la interacción con el otro y con el territorio. Entre los mapuche y, también, entre otros pueblos originarios, el yo se subordina al colectivo. $Y$ el colectivo, ya lo sabemos, es la comunidad, la tierra y los seres que la pueblan. 
Caso aparte, es el de una o un "kalku" en extremo malvado. Personas que hacen el daño pueden ser enjuiciadas y condenadas a muerte.

No estamos frente al mismo caso de las atribuciones de daños y maleficios que se hicieron a la bruja europea. Tal como dijimos esa fue una ficción. Es realmente increíble que seres humanos creyesen que las brujas iban volando al aquelarre, que se juntaban con el demonio y tantas y tantas mentiras más. Hay un juicio, guiado por De Lancre, donde dos acusadas confiesan que tenían unos sapos que les avisaban cuando era hora de "ir a brujear". Esas mujeres fueron condenadas a la hoguera en base a la tan singular confesión (en Logroño, el año del señor de 1608). En cambio entre los mapuche no existe nada parecido a la demonología, pero sí tienen muy claro que hay energías malignas en el universo (lo que conocemos como "mala onda”) y una "kalku” puede manejar esas energías lanzándolas contra la gente, los bosques, la tierra. Esta es una cuestión concreta, muy diferente a salir volando de noche a juntarse con un demonio con cola de flecha o dotado de alitas de murciélago, tal y como los pintaban los demonólogos del medievo.

De regreso a la descripción nos encontramos con una cuestión relevante. Una atribución que llegó con la Conquista y que sirvió de pretexto para desatar la batida contra la gente que vivía en América. El texto de Brunet anota: "Y desde allí repartía su saber diabólico" (257).

Q: Aquí se equipara abiertamente a la machi con bruja europea del aquelarre. Asoma así la demonización europea de las religiones otras. En general, los invasores intentaron homologar la espiritualidad de los pueblos originarios a lo que dice su propia religión. El saber de Occidente se relaciona con la luz. Los otros pueblos son la antítesis. Sus saberes son obscuros y diabólicos. Ahora, el problema del demonio: el demonio no existía en América, llegó junto con los europeos. No hay ninguna conexión entre los saberes chamánicos y el diabolismo, pero pareciera que el cristiano requiere la presencia del demonio. Los primeros trabajos de los sacerdotes de la religión imperial fueron mostrar imágenes del infierno, del diablo, de los tormentos infernales a los indígenas. El demonio, según la religión católica, guiaría la espiritualidad mapuche. La ecuación que se ha expresado en diversas oportunidades: indígena=demonio, se hace carne en el texto. 
La desgracia que acarrea esa terrible ecuación es que condena a la clandestinidad los rituales y la espiritualidad. La dimensión espiritual de la vida mapuche se debe practicar en forma oculta. Y si la espiritualidad es la base de la relación, de la sujeción ontológica del mapuche con el cosmos, el demonizar sus prácticas corta el cordón umbilical del mapuche con el mundo.

Importa sobremanera insistir en que la tragedia de perder la espiritualidad para los mapuche es fruto de una invención. La crítica especializada ha mostrado con largueza que la constitución de Satán, como lo conocemos hoy, es un invento, una excrecencia de la caza de las brujas.

Destacamos que tras la singular atribución demoníaca a la bruja del relato, viene otra muy propia de los occidentales, desde Platón y su batida contra los sofistas que vienen acusando al oponente simbólico de querer el lucro. En el cuento se anota que la machi era "bien pagada por quienes requerían sus servicios" (27).

Q: Aquí hay un punto fundamental, ellos hacen trabajos solamente cuando se lo piden. Nunca, jamás hacen trabajos por cuenta propia. En general, los mapuche son respetuosos del otro. Y especialmente, respetan la vida. De ahí que atribuir a la machi el interés por una venganza ajena sea imposible desde la lógica mapuche. La machi aparece como un engendro que sólo piensa desde lo malo.

Creo que es elocuente observar como el texto carga constante a la machi con semas de maldad y de perversidad. Si extrapolamos esta discusión, notamos que la cultura wingka ha desarrollado una herramienta poderosa para oscurecer al diferente. Pero de paso, esa estrategia también revela la incapacidad absoluta del occidental de ver su propia imagen. Hablo de esa imagen temible, tan destructora, tan destructiva. Y pareciera que ella se exorcizase al atribuirla al otro.

\section{Los ritos}

El cuento, luego de la serie de atribuciones comentadas, dará cuenta en concreto de las acciones de la machi. Así aparece un primer rito en el cuento. Leemos: 
dejó el tarro en el suelo, se alzó y extendió las manos con las palmas abiertas sobre el agua. Entonces los labios salmodiaron una especie de melopea que terminaba con un gemido cada vez más alto, cada vez más desgarrador (257).

Q: Estamos frente a un rito claramente, pero su carácter me es extraño, pues no existe una ortodoxia en la ejecución de un ritual, cualquiera sea, entre los mapuche. Fundamentalmente porque la relación con los diferentes espacios (cerros, aguas, bosques) se da a través de rituales. Los rituales son instrumentos de relaciones sustanciales, profundas y reflexivas. Por otro lado, la melopea que terminaba con un gemido cada vez más alto, es claramente una muestra de la forma en que el wingka escucha, entiende el lenguaje ritual mapuche. Sin intentar comprender nada de la lengua y los usos dados a ella.

Confirmamos el carácter ritual del acto en las acciones que desarrolla la machi:

Las manos empezaron a trazar signos extraños en el aire. El cuerpo seguía fijo, ceñido por el chamanto que desde los hombros le llegaba hasta los pies desnudos, cruzados ahora uno sobre otro. La cara guardaba la misma inmovilidad de piedra que tenía el cuerpo y sólo los brazos aspeaban cábalas en movimientos rápidos (258).

Q: Esto también puede ser posible, pero no reconozco un ritual en específico. Los pies desnudos hablan también de una observación exógena mapuche. Para los wingka el andar descalzo es seña de pobreza, falta de medios. Mientras que para los mapuche es algo totalmente irrelevante. Siempre se anduvo descalzo hasta muy entrado el siglo pasado, inclusive en la actualidad para algunos rituales es menester quitarse el calzado para lograr una mayor conexión con el medio.

Importa destacar las siguientes líneas, pues la joven se incorpora en la escena:

La muchacha siguió mirando desde su atalaya. La Machi lentamente dobló las rodillas, hasta quedar sentada en los talones. Parecía serle familiar esta postura en que se la sentía cómoda. No canturreaba y un largo rato estuvo así, inmóvil en el silencio (258). 
Q: La machi asume una posición ritual. Nosotros sabemos que en todo rito, no sólo el rito mapuche, la corporalidad del sujeto también debe entrar en la fase de la comunicación con el entorno. Sin embargo, el asumir una posición antes del rito no es muy propio de la catolicidad dominante en Occidente, excepto el arrodillarse. Debo consignar que un mapuche sí se puede arrodillar durante un ritual. En realidad no tenemos certeza de cuándo este acto de arrodillarse fue adquirido, es decir, postcontacto o siempre existió en el ritual. Explorando en el asunto, pienso, por ejemplo, en el concepto de "lukutun" que significa arrodillarse en ocasiones de ritual. La posición también se alude en los diseños de la faja y se designa como "lukutuwe", lugar de arrodillarse (la faja es una prenda muy propia del mundo mapuche. Consiste en un cinturón de lana marcado con una serie de dibujos y trazos complejos, cargados de amplios significados. Se usa amarrado en la cabeza).

Q: Si vamos a otros lugares, recordamos que los mayas tienen un rasgo de sentarse frente al fuego. Otra forma que se puede rastrear entre la gente es sentarse con los pies juntos (cuando José dice la gente, habla de los pueblos originarios).

Q: Esta última es una posición muy propia de los antiguos mapuche generalmente para conversar, descansar, pensar, aconsejar, meditar.

Ahora, el relato pasará a exponer en extenso las actividades "mágicas" de la machi. Y ya con la joven plenamente incorporada:

Entonces una rana empezó a croar. La muchacha la sintió tan cerca, que la creyó al otro lado de las quilas, junto a la Machi, que seguía sentada sobre los talones, con las rodillas juntas y las manos rodeándolas, alta la cabeza... La rana croó nuevamente y la muchacha tuvo un escalofrío al ver que los labios de la vieja se movían y que era ella quien daba a la montaña el canto monocorde.... porque se hablaban, de eso estaba la muchacha segura: la vieja entendía lo que decía la rana; ésta contestaba las preguntas de la vieja...

Por tres veces se repitió la escena. Croaba la vieja y una rana, aparecía como imanada sobre las piedras, manteniendo el diálogo hasta el momento en que la Machi buscaba entre los ojos algo que por fin encontró, porque se puso en pie con la rana entre las manos, rezumando júbilo por el tajo enorme de la boca. Medio lleno de agua el tarro, echó, dentro la rana, colocó aquél sobre su cabeza y andando a pasos lentos, erguida 
y mayestática, subió la cuesta hasta desaparecer en lo alto, fundida a las sombras de la noche que se espesaba (258).

Q: Aquí no hay nada del mundo chamánico ni tampoco del mundo mapuche. Incluso, el cántaro en la cabeza es propio de las selvas centroamericanas. "Múcura" es su nombre. Una "múcura" es un recipiente de barro arcilloso, similar a la botija, de tamaño mediano, con largo y estrecho cuello y pie esferoide como en las ollas. Se trata de una vasija precolombina usada para recoger, beber y almacenar agua, chicha, cereales. Simbólicamente es una representación de lo femenino, más concretamente del vientre de la mujer. Es también pieza de ajuar en los ritos funerarios en diversos países de Iberoamérica. En el caso mapuche, lo más similar a un cántaro sería el "metawe", el que, como su nombre lo indica, es un recipiente de greda que se lleva en brazo.

Me interesa sobremanera marcar la referencia al tajo enorme de la boca, pues es una marca de racismo máximo: las "indias" no tienen boca, tienen un tajo...

\section{El encuentro y la captura}

El ritual de la vieja no fue inocente, tenía un objetivo no declarado: seducir a la joven. Atraerla. Así:

el día siguiente la muchacha la buscó en su guarida, entre los altos robles de la montaña. La llevaba una curiosidad aguda, el deseo de ahondar en esa vida llena de ritos, de acercarse a esa alma solitaria que vivía aislada por el pavor de los demás, sin otro contacto con los humanos que los breves momentos en que aquéllos iban en busca de amuletos, de brebajes, de ensalmos (259).

Q: Pareciera que la muchacha es atraída por el conjuro hacia el lugar de la machi. El aislamiento, como te decía, es propio de los "kalku”, a diferencia de la o el machi que siempre está en contacto con su gente con la comunidad y cuyos ritos, como anotábamos, son abiertos, públicos.

Importa destacar otra marca de racismo. La machi tiene guarida, no casa. 
Luego, el texto nos describe el lugar donde estaba la casa o la ruka:

cerca del río que iba por el fondo del tajo y junto al camino abandonado que otrora llevaba a la Argentina, la, casa se alzaba solitaria, sin ningún otro edificio en torno, sin ninguna manifestación de estar habitada. Ni un cobertizo ni una maceta, ni un animal, ni una chacrita. Nada. La casa con sus cuatro paredes de piedras superpuestas, groseramente unidas, con el techo de quilas y totoras. Y la montaña por todos lados tocando casi la casa, apretándola con su vegetación espesa, engarzándola con el verde de sus hojas, protegiéndola con la guardia de los troncos rugosos (260).

Q: Descripción muy extraña, pues habla de una zona pehuenche, pero Hualqui está en el lugar de los lafquenche, en la costa (la referencia al camino hacia Argentina muestra que el texto habla de la Cordillera de los Andes, zona donde habita la cultura pehuenche).

Ya en los dominios de la machi:

la muchacha ató las riendas del caballo al tronco de un árbol y avanzó hasta la puerta de la casa, es decir, hasta el vano en que debía estar la puerta. Se asomó adentro y preguntó:

-¿Se puede entrar?

No contestó nadie. Un gato avanzó silencioso en sus calcetas blancas, lustroso y negro todo él, verdes las lentejuelas de los ojos indiferentes; se sentó en el umbral, arrolló la cola en torno a las patitas y se quedó muy quieto haciendo de esfinge (260).

Q: La casa no tiene puerta, puede ser una característica de la ruka. Sólo hay un vacío. La puerta se adquirió con el contacto. Antes las rukas tenían un cuero en la puerta y éste se sacaba en el día. La presencia del gato es claramente una contaminación occidental que proviene de la imagen clásica de la brujería. La bruja tiene como aliados a los gatos en el imaginario europeo.

La joven insiste en entrar en los terrenos del peligro:

La muchacha volvió a preguntar:

-¿No hay nadie?

Y como de nuevo no contestaran dio un paso que la colocó dentro de la pieza única de que constaba la casa, una habitación cuadrada de techo 
muy bajo, de paredes desnudas, con un camastro en un rincón y unos cajones repartidos aquí y allá en un desorden en que había limpieza. En el centro se quemaban unos carbones en el hogar, montón rojo entre poyos de piedras, con un trípode encima en que una olla de greda barbotaba su hervor. En un extremo lucía un telar indígena con un choapino comenzado en colores chillones (260).

Q: Hasta aquí llegó la casa como ruka. El espacio es cuadrado, entre los mapuche no hay nada cuadrado. Las rukas son curvas, ovaladas. Un detalle: la casa es limpia. Es extraño que marque con un sema positivo a un personaje como la machi. Aparece también, la clásica imagen del caldero de la bruja. Lo raro es que los calderos ya eran de fierro. En cambio la olla del cuento es de greda. Con respecto al choapino, también pareciera una contaminación con el mundo pehuenche, pues los colores fuertes son propios de esa parte de la cultura mapuche.

La joven empieza a perder las esperanzas:

Como adentro no había nadie ni nada que atrajera su curiosidad, un poco desilusionada la muchacha salió de la casa y frente a ella, se quedó pensando en qué haría, ya que probablemente la Machi no estaba por allí, sino en tren de buscar animalejos o hierbas (261).

Q: El machi no usa animalejos, usa hierbas, pero no animales. Aquí también se podría reconocer una marca de "kalku", pues ellos usan animales, como aves, etc. Son aliados. Hay uso de animales y aves en los rituales, pero siempre esos animales son usados como un otro más dentro del ritual. Al llamarlo como animalejo, nuevamente observamos una descripción peyorativa de estos seres vivos.

Me interesa destacar la forma en que el análisis de una serie de detalles descriptivos nos llevan a encontrar un subtexto en el texto de Brunet. Subtexto que es una historia otra. Pareciera ya no ser la historia de una machi, sino de una "kalku".

La siguiente escena es muy relevante. Confirma que la machi se hizo la desentendida en el río. Ella sabía que estaba la joven. Vamos al relato:

De pronto, a espalda de la muchacha una voz preguntó:

-¿Qué busca?

La muchacha se volvió rápida. Allí estaba la Machi, alta y cenceña, 
saliendo de la negrura del chamanto que esta vez la ceñía de pies a cabeza.

-¿Cómo está, señora?

-Me llamo la Machi de Hualqui y no quiero otro nombre.

-¿Cómo está, Machi? Venía... Venía...

Y no supo qué decir, porque los ojos de la vieja, brillando bajo la visera que le formaba el chamanto, tenían un brillo metálico penetrante que parecía meterse muy hondo por los ojos hasta verle adentro el pensamiento más recóndito (261).

Q: Nos enfrentamos a un asunto muy interesante que pareciera confirmar que la Machi es una proscrita, pues destaca su gentilicio. Habría que suponer que anteriores fechorías la exiliaron de su mundo. Por ello insiste en destacar su gentilicio antes que su nombre. Ahora si es una proscrita, significa que hizo daño, por ende la machi del relato es tal, es una "kalku”.

En otro orden, interesa destacar que cuando se inicia el diálogo entre la joven y la bruja hay una atribución abiertamente racista. Leámosla:

La vieja dijo con su voz sorda, que parecía moler las palabras hasta dejarlas convertidas en harina de sílabas que no tenían sentido (261).

Q: Evidentemente se refiere a la machi hablando mapudungun. Lengua que el relato reduce a "palabras de harina".

Luego usará el castellano para dirigirse a la incauta:

Feo vicio el de la curiosidad. Ayer me vio junto al remanso en busca de ranas y de ahí que hoy venga a ver cómo es la Machi de Hualqui. Y la Machi de Hualqui es una mujer como otra cualquiera, un poco más vieja y un poco más triste que cualquiera, solamente. Eso es todo. Váyase ahora.

La muchacha protestó.

-Es que yo... Yo no tengo la culpa de haberla visto ayer... Es que quisiera... No he venido solamente por lo que usted cree... Quisiera...

La vieja sonrió y una gran $\mathbf{O}$ negra se le marcó entre las arrugas de la cara. Dijo:

-Deme la mano (261).

Q: La machi destaca que la curiosidad no es una virtud, es un vicio. Entre los mapuche es muy mal visto el fisgonear. Le da incluso la posibilidad de irse. Existe un recurso retórico para culminar o continuar una 
relación. Entre los mapuche, en algunas ocasiones, se advierte al otro que se encuentra en una situación de riesgo. Ese riesgo puede provenir del mismo que hace la advertencia o de un tercero. Fíjate que de nuevo la boca, ahora en $O$, es muy extraña, salvaje.

La joven está indecisa, pero finalmente se queda. La boca nuevamente aparece como muy peligrosa. Antes era un tajo, ahora es una cueva, una caverna obscura negra.

Q: Aquí nos queda la duda, ¿a qué fue la niña? ¿Era sólo curiosidad? ¿O fue allí porque quiere conseguir algo de la vieja?

En las líneas que siguen vemos a la muchacha ya capturada y la respuesta a la inquietud de Quidel: "Entre las manos cobrizas y duras de la Machi, la mano de la muchacha era blanca, suave, con uñas de concha de perla lustrosa" (261).

Q: Las manos de la machi son descritas como duras, cobrizas, propias de la relación con el entorno, en contraste con las manos de la niña. $\mathrm{Ma-}$ nos ideales, blancas. Conformes con la obsesión racista y clasista de las elites latinoamericanas. Las duras manos de la vieja revelan que ella se enfrenta a la vida, una vida dura. La joven no desciende al trabajo, otros luchan por ella.

Continúa la inquietante escena:

Fue mirando las líneas que surcaban la palma y por fin otra $\mathbf{O}$ grande le manchó la cara. Y dijo:

-Cordera buena como la mía... También tiene el abandono de un hombre que la hizo sufrir, que la dejó por otra. iPobrecita linda! Pero ya no habrá más alegría para ese hombre, no habrá más, no habrá... Entre (262).

La mención a la "cordera buena como la mía" la encontramos, en una situación muy similar, en otro cuento de Brunet, "Ojo feroz" (1962). Allí también hay una machi que ve sufrir a una joven por un hombre. Hablamos, entonces, de un relato hermano del que comentamos. Leamos la descripción de la machi que aparece en "Ojo feroz":

La vieja la observaba con su ojo único, puesta de perfil y como las aves con la mirada al sesgo, fija y dura. Tenía de pájaro sólo eso: el mirar. La cara ancha, de pómulos salientes y nariz chata, acusaba el mestiza- 
je... las greñas blancas que a la manera india le caían en dos trenzas por la espalda. Las arrugas le barbechaban la piel requemada... Nunca podía vérsela de frente. Buscaba la línea que mostrara el perfil, y entonces la mirada iba como flecha a clavarse en el blanco del que hablaba (247).

Los subrayados son nuestros. Con ellos mostramos las similitudes con la machi del relato que comentamos. Esta "vieja" es muy similar en su accionar a la Machi de Hualqui: cobra por sus servicios, hace un daño a un hombre, vive alejada del mundo... otra "kalku".

Q: De regreso al relato se observa que la vieja decide que la joven en algún sentido es ella y por ende, castigará al que la hizo sufrir. Esta es una "transferencia". Aquí hay una identificación. Al mismo tiempo se sanciona la venganza. Ahora la joven es materia dúctil entre sus manos:

Le indicaba la casa. Como sugestionada por el gesto la muchacha entró. Desde ese momento lo que fue pasando, lo que fue haciendo, lo que fue diciendo, lo vivió como en un sueño, como en esas pesadillas en que se obra a pesar nuestro, contra nuestra voluntad, forzada por poderes con los cuales no vale luchar (262).

Q: La niña entra en un estado hipnótico, pues ingresa a un espacio ritual. Su siquis no está acostumbrada a estar en lugares donde confluyen varios planos de la realidad, lugares que responden a otras reglas, una realidad que para el occidental es imposible. Sin embargo, esa realidad está ahí, y en ella se agitan fuerzas incontrolables (creo que se refiere a algo similar al "afuera" del que nos habla Foucault (1997).

Es muy sugerente explorar las aristas mágicas del pensamiento de los filósofos. Aristas ocultas, veladas, pero muy presentes. El caso de Deleuze y Guattari es claro, pensemos que en Mil mesetas (1996) incluye un apartado titulado "recuerdos de un brujo". Foucault es más prudente. Pero si examinamos con rigor un texto como El pensamiento del afuera (1997) notamos como se infiltra allí un saber mágico. Saber muy similar a los que nos comparte José. Me refiero al momento en que, a partir de Hölderin, nos habla de la exigencia de: "de humanizar la naturaleza, de naturalizar al hombre y de recuperar en la tierra los tesoros que se habían dilapidado en los cielos" (28).

Q: De regreso al cuento, notamos que la mente de la joven es inocente, 
ella siempre ha estado protegida. El daño que produce la sobreprotección se marca en este punto, la mente no sabe defenderse. No sabe construir para sí misma (mantengo la estructura de la frase tal y como la pronuncia José). La niña está queriendo sin querer... se deja llevar por otra parte de ella. Ello ocurre en clara oposición a la siquis de la vieja que es de una autonomía absoluta. La vieja ha logrado sobreponerse a la vida. De ahí que ella pueda hacer lo que quiere con la cordera. La vieja no está en el plano de la materialidad, trabaja en el plano subjetivo.

De ahí que le importa nada que la casa tenga puerta o no, la casa es sólo un cobijo. Los brujos dominan esos planos, la suerte, la alegría, la pena, el deseo. Ellos manejan las claves para atraer o alejar esas energías. Entre las fuerzas que manejan es posible incluir, incluso, a la muerte, son capaces de dar o retardar la muerte.

\section{El segundo rito}

Ya con la muchacha dominada, la machi inicia un segundo ritual:

-iSiéntese! -Y le señaló una silla junto a la mesa en que acababa de extender un paño negro con una cruz blanca en el centro.

La muchacha se sentó y esperó ansiosa, toda ojos anhelantes, clavada allí y sintiendo, sin embargo, el deseo violento de huir.

-Dibuje aquí al hombre que la abandonó y que la hizo sufrir, tratando de que resulte lo más parecido posible.

El lápiz fue trazando los rasgos de la fisonomía, de la silueta. Era pintora y el retrato "del hombre que la abandonó y que la hizo sufrir" era una pequeña maravilla de parecido.

Cuando terminó el dibujo se lo quedó mirando, y ante esa imagen que la observaba desde el papel con los ojos profundos de terneza que ella le conociera, los suyos de agua clara se humedecieron de llanto. La vieja dijo:

-No llore la cordera linda. Ya la Machi de Hualqui sabrá vengarla (263).

Q: En el ritual aparece una atribución dada por sincretismo que existiría entre la brujería mapuche y la demonología, pues el paño negro y la cruz son propias de los rituales de adoración al demonio. (La "la bruja 
reza pero no a Dios" escribe un witchcraft, cazador de brujas, inglés). El ritual es propio de la hechicería simpatética, en que es necesario un objeto o una imagen. Entre los mapuche ello es así. Al dibujar (su habilidad revela que es muy educada) al sujeto, la niña se entrega. Las lágrimas que vierte de sus ojos claros, nueva atribución a la clase de la joven, son por el poco amor que le queda. Ella llora porque lo está vendiendo. Y, por otra parte, la vieja nuevamente se llama a sí misma como machi. Está obsesionada con la venganza, en cada una de sus acciones actualiza su propia venganza.

Si vamos al texto, se confirman estas apreciaciones:

La muchacha preguntó:

-¿Qué va a hacer?

-Vengarla.

-No quiero daño para ese hombre.

En los ojos de la Machi se encendió una chispa de alegría borracha. -iJa! iJa! iJa! (263).

Q: La alegría borracha revela la presencia del rencor. Alegría que aparece por la venganza. Es una alegría atípica, no feliz, no surge desde su corazón. Nace de la venganza.

La muchacha se asusta:

-No quiero daño -insistió.

-Cállese y haga lo que le digo -la voz se había vuelto de metal duro y los ojos imponían su voluntad a los ojos claros que no podían hurtarse al mandato.

-Piense que este retrato no es el retrato, sino que es el hombre mismo. Piense. Piense. Piense (263).

Q: Aquí se transforma, aparece la fuerza de la "kalku". Domina plenamente a la joven. La machi pone en ejecución sus saberes, algo que los brujos saben desde siempre: usar la potencia del pensamiento. Y la repetición también es propia de la brujería: piense, piense, piense. La repetición tiene una razón de ser. El alejar otras energías.

Luego dará inicio al dudoso rito:

Sobre la mesa había colocada una palangana grande tapada por un lienzo blanco en que había una cruz negra. Levantó el lienzo y apareció 
una rana sentada en el cuarto trasero, verde pintado de negro el lomo, blancas las patas y la panza. Los ojos tenían un estrabismo que fijó la atención de la muchacha. En la frente le brillaba algo, no supo qué, una especie de protuberancia que parecía una pupila ciega (263).

Q: Esto es poco claro, pues anteriormente la cruz era blanca y el lienzo negro. Hay una inversión. Importa destacar que para algunos cristianos la cruz es un objeto inmundo que no pertenece al Reino de los Cielos, pertenece a la oscuridad. Veamos un ejemplo: "Cristo nos redimió de la maldición de la ley, hecho por nosotros maldición (porque está escrito: Maldito todo el que es colgado en un madero)" (Gálatas, 3: 13). Postulo que desde aquí se puede justificar su uso en rituales "paganos”. (Por nuestra parte anotamos que nuevamente aparece la rana clásica. La misma que fue a cazar. Continúa el desarrollo del rito):

La Machi tomó el papel en que dibujara a "ese hombre” y lo plegó en varios dobleces triangulares, al par que iba diciendo palabras molidas, entre las cuales intercalaba el canturreo de la tarde anterior. Colocó entonces los pulgares sobre los ojos de la rana y el canturreo se desenvolvió en siete trozos, dichos en siete tonos. La rana parecía hipnotizada. Entonces la vieja le abrió la bocaza y la hizo tragar el papel doblado. Luego -siempre diciendo las palabras canturreadas en los siete cambiantes tonos- tomó una aguja en que había un largo hilo hecho con la tripa de un gato negro y fue cosiendo la boca de la rana con siete puntadas, a cada una de las cuales correspondían siete nudos. La rana no parecía sufrir, no se debatía entre las manos que la martirizaban. Cuando la Machi la abandonó sobre el lavatorio, se quedó inmóvil, sentada, con las patitas delanteras metidas entre las traseras. La boca tenía un débil estremecimiento y los ojos cada vez más abiertos, más fijos, no se separaban de los ojos de la Machi, que la miraba intensamente, aún con las palabras de la cábala en los labios (263).

Q: Nuevamente hay marcas de contaminación occidental, de confusión entre el mundo mapuche y la visión que tienen los wingka de nuestra cultura (el triángulo como forma mágica viene del antiguo Egipto y de los postulados mágicos de Pitágoras. Es un símbolo muy poderoso. Baste pensar en el triángulo masónico que está al reverso del billete de dólar... La presencia de la rana, insistimos, es una muestra más de la contaminación con la superstición europea que vincula a esos animalitos con las brujas). 
Me interesa destacar que hay una segunda mención a las "palabras molidas". Es el mapudungun. Es una forma racista de hablar de la lengua. En cuanto al canturreo es propio del ritual mapuche, se trata de una melodía que a veces no contiene palabras sino que a veces sólo sonidos que se repiten. Aquí aparece, nuevamente, un ejercicio que permite invocar la fuerza del pensamiento.

Nos acercamos al fin del rito:

Hubo un largo silencio. La muchacha sentía que la cabeza se le iba, que vacilaba todo a su alrededor, que aquello que tomara como un motivo de curiosidad y de esperanzas de no sabía qué, se iba tornando en un verdadero espanto. Seguía clavada en la silla, mirando a la rana y pensando en "ese hombre". Eso era lo que hacía y pensaba con una voluntad que no era la suya. Porque en el fondo, con los restos de su voluntad quería dar los pocos pasos que la sacarían de allí y los otros que la llevarían hasta el caballo para huir lejos de aquello. Había que huir, sí, había que huir, quería huir, pero no podía. El cuerpo estaba inerte sobre la silla, los ojos no se separaban de la rana, el pensamiento estaba fijo en una materialización de "ese hombre" (264).

Q: Percibe que desató una fuerza que no puede controlar en absoluto. El ritual está en pleno curso, el espacio inundado por el ritual. Todo se mueve en función de las energías. Pierde la voluntad y el control del pensamiento.

El clímax:

El vientre del animalejo empezaba a hincharse. La boca se festoneaba de baba. Las patitas pataleaban débilmente. Por los ojos pasaban ráfagas de sufrimiento. Pero no se movía, siempre sentada. Seguía la hinchazón. La baba se hacía espuma. Los ojos se salían de las órbitas. Iba a reventar. La Machi empezó de nuevo su canturria. Las manos hacían signos en torno a la cabeza del animalejo. Iba a reventar. Iba a reventar. Los ojos se desorbitaban. La piel se rajaba. Entonces, en la protuberancia que había entre los dos ojos de la rana y que cada vez se hacía más transparente, que cada vez tomaba mayor apariencia de una tercera pupila, en el preciso momento en que la rana reventaba, la Machi le clavó siete veces un alfiler de cabeza negra (264).

Q: Claramente estamos frente a un ritual que nada tiene que ver con el mundo mapuche, como ya he destacado. Sólo me interesa marcar que 
ahora es claro el asunto de la risa. Es de satisfacción por hacer daño. Como se puede ver en lo que sigue:

Luego se volvió a la muchacha y dijo con su risa horrible:

-Váyase tranquila. Ya está vengada. Ya ese hombre no podrá hacerla sufrir más.

-¿Qué ha hecho? ¿Por qué ha hecho esto? -preguntó la muchacha, que empezaba a tomar dominio de sí misma.

-¿Qué he hecho? Vengarla. ¿Por qué? Porque les tengo lástima a las corderas blancas como usted, que penan por el olvido de un hombre. Cordera blanca la mía, zarca como usted, hija de caballero, con corazón de panal, y me la mató un hombre con sus desdenes, luego de haberla embelesado con palabras de amor... Pero la vengué... La vengué como pude... (264).

Q: Lo primero que hay es una solidaridad de género. La machi considera que el hombre mató simbólicamente a la niña. Ella asumió el papel de cordera sacrificial. Murió en el altar del machismo. Y vincula este hecho con su propia historia en el momento que habla de cuando su hija fue traicionada (asunto que queda muy claro en "El ojo feroz", relato hermano del que comentamos). Entonces la venganza se hace absolutamente necesaria. El ritual es contra el hombre que hace sufrir a una mujer. Dentro de la segunda historia, del subtexto. La machi es una vengadora de las mujeres. La venga como puede, cuando dice esto reconoce la debilidad femenina. La machi no ve la diferencia social, sólo ve en la muchacha una mujer traicionada, al igual que ella. No le cobra.

Ahora viene una parte muy importante:

Aprendí años de años este arte mío de los ensalmos. Me llaman bruja... Me llaman la Machi de Hualqui... No importa, no quiero otro nombre... Aprendí en las islas, allá lejos, en los canales de Ancud, toda la ciencia que da el poder del Bien y del Mal. Condenada estoy, lo sé... pero con el goce que tuve de vengar a mi cordera linda, ya tengo para endulzar todas las penas venideras, así sean las del infierno... Nunca he hecho el mal sino para vengar a corderas como la mía y como usted... Váyase tranquila... No me debe nada... Estamos en paz... (264).

Q: Gracias a estas palabras podemos (junto a mi colega) reconstituir la historia y entender por qué la machi devino "kalku". Ella fue machi, 
vivía en Hualqui, pero un hombre se aprovechó de ella usando palabras de amor. Ella para aprender a vengarse se fue al sur, donde los brujos de Chiloé. Luego, la misma venganza le acarreó la condena. Y dejó de ser una machi, lo reconoce, y se transformó en una "kalku". Al principio se declara la machi de Hualqui: "Me llamo la Machi de Hualqui y no quiero otro nombre". Ahora, ya no le importa, ella sabe que ya no es una machi. Ella está obsesionada por el mal, es una vengadora de mujeres. Esa es su misión. Pero la vida es dura, por ende, ofrece sus saberes, servicios, a cambio de una paga. Pero en este caso, no cobra, reafirmando que la venganza es personal. El desamor, la traición a su corazón, a su humanidad fue la causante de su transformación, de su renuncia a una forma de ver y reconstruir el mundo. Hablo de la fantástica capacidad de los chamanes de renovar constantemente las relaciones del humano con el todo y del todo con los humanos. Pero optó por la destrucción, por la venganza. Fuerzas desatadas por un desamor nunca superado.

La machi estaba feliz, pero la muchacha queda en shock:

La muchacha no supo cómo salió de la casa de piedra, cómo llego hasta el caballo y montó en él... sentía una especie de mareo, un girar de la montaña en torno suyo, una superposición de imágenes en que estaban los ojos del gato, los ojos de la Machi, los ojos de la rana. Luego se veía a ella misma, como si se mirara desde fuera, desdoblada, y se veía cerca de la mesa, mirando aquel tercer ojo que le brotaba a la rana en media de la frente... Y le daba angustia el prever que de pronto los árboles la cercaran, cerrando el círculo en torno suyo, dejándola ahí prisionera, ahogada por los troncos que se hacían compactos para mejor encerrarla, por las hojas que formaban una maraña espesa y consistente (264).

Q: La muchacha está traumatizada, lo que hizo no hizo bajo su voluntad. Se escindió su espíritu. Evidentemente la otra parte de ella estaba de acuerdo, fue aquella parte de la que se hizo cómplice la "kalku". Ahora es importante destacar que el caballo la llevará de regreso a su espacio. El texto reconoce el saber de los animales.

Ya en su casa:

un mozo ayudó a la muchacha a bajarse en el patio de la casa. Vacilando pudo llegar hasta una de las sillas largas que se extendían en los corredores coloniales y allí descansar de su extraña aventura. Tenía la 
impresión de estar viviendo dos verdades, dos vidas paralelas: La suya habitual en la placidez de la casa, entre los suyos burgueses, realizando los gestos de siempre y diciendo las palabras de cada minuto, y otra vida que había empezado allá en la casa de piedra de la Machi, una vida dependiente de un alma de pavura, llena de sobresaltos, inquieta de presagios, agobiada por no sabía qué remordimientos (264).

Q: Se comprueba que está partida, la machi le partió el alma. Se comprueba, también, que es una joven de clase alta. Pero cometió un error, se fue al lado salvaje, "incivilizado". Lugar donde llegó por la condición en que la dejó el desengaño amoroso.

Ese desengaño la llevó por caminos que es mejor no transitar. Se observa la pugna de dos ideologías en el relato: una de género donde se critica el actuar de hombres que usan a las mujeres como una cosa y otra, la ideología dominante del realismo que termina por triunfar. Ideología que nos dice que hay que imponer la civilización, en lo indio está el peligro. Así la joven que tuvo contacto con lo indio ya no realiza los gestos de siempre, ni dice las palabras de siempre: perdió los gestos y las palabras blancas.

Ahora asistiremos a la confirmación de estos desarrollos:

En la mañana siguiente la prensa de la capital trajo la noticia: "Ayer ha dejado de existir repentinamente de un ataque al corazón el señor...” Un hombre ilustre en las letras, frases de condolencia, la biografía del extinto, un retrato en que asomaba la cara filuda con la gran frente pensativa y los ojos perdidos en las sombras de las cuencas hondas, con la boca sensual y dura y la barbilla cuadrada de voluntarioso (264).

Unas líneas más arriba el texto, por boca de la machi, se permitió descargar toda su ira contra el sujeto que causó la desgracia de la joven. Y no sólo contra él, sino que en una solidaridad de género amplió la condena a todo aquel que haya causado la desgracia de una mujer. Sin embargo, como ya apuntamos, el realismo siempre se inclinó por el orden del mundo. Aquí estamos ante una marca concreta de esa inclinación. Le comento a José este asunto.

Q: Es evidente, el hombre es descrito como un hombre de letras, de frente ancha, compáralo, por favor con el rostro y la boca de machi: boca sensual v/s tajo-hoyo. Además tiene la frente pensativa, frente arrugada, la barbilla cuadrada, voluntarioso... es importante como se describen los 
rasgos, de cómo se hace presente una estética por sobre otra, de cómo se privilegia una de la otra. Una representa lo culto, lo hermoso versus la barbarie y la fealdad.

$\mathrm{Al}$ leer sobre la tragedia del hombre que había causado su desgracia, la joven se derrumba:

la muchacha se quedó mirándolo, mirándolo. Las letras empezaron a bailarle ante los ojos. El retrato giró y quedó al revés, cabeza abajo. Dio vuelta maquinalmente al diario. Las letras seguían bailando. Sintió que dentro de ella se derrumbaba algo y dio un grito. Se caía algo, sí, se caía algo dentro de ella. Se caía su personalidad, la de la muchacha en la casa de campo, entre los suyos serenamente burgueses. Y quedaba en pie la otra muchacha que naciera en la casa de piedra, con el alma tenebrosa y llena de espanto (264).

Q: Por favor nótese que invierte el retrato, aún actúa la brujería. Claramente el contacto con el "otro indio" trae las mayores desgracias a los civilizados. La joven quedó con su alma partida porque tuvo contacto con lo salvaje. Los burgueses son serenos, pero ahora está dominada por el alma salvaje tenebrosa y llena de espanto.

El relato finaliza con la tragedia de la joven:

Desde entonces, en la casa del fundo en que la muchacha vivía tan plácidamente con los suyos -el sentimiento hecho trizas se disimula muy bien en la indiferencia de los demás-, hay una pobre loca de claras pupilas visionarias, tranquila y acogedora, que se pasa los días vagando por los corredores, por las habitaciones y por el parque, seguida de una nurse que la cuida, y cuya inocente manía es acercarse a todo animal y buscarle algo entre los ojos. No habla. Suele canturrear una especie de melopea, y a veces, en los atardeceres en que la luna decora el crepúsculo, gusta de bajar el ribazo del río y cerca del agua croa a la par que las ranas, sentada en una extraña pose que la hace semejante a ellas (264).

No editaré lo siguiente, pues es muy propio del modo del hablar de los mapuche, es una especie de habla "desatada", mezclan las ideas, las opiniones, los saberes, pero finalmente todo tiene sentido, mucho sentido.

Q. Se comprueba que ha perdido su alma, delicada. Se vuelve loca, pero ella ha adquirido otras cualidades, habla con los animales. Busca entrar a la naturaleza, quedó con la inquietud por los saberes ocultos, de 
hecho baja al río con la luna llena. Pero no puede asumir lo que asumió la machi, ser fuerte, decidida, luchar contra la vida. Es muy diferente la forma de asumir la tragedia, cuando la machi sufrió lo mismo, partió a Chiloé a buscar fuerza. Pero ella no, ella responde al modelo occidental, no tiene arma alguna para lograr la independencia. Estaba condenada a casarse con un hombre luchador, voluntarioso y cumplir con su papel de esposa. La sociedad no la preparó y tampoco fue capaz de enseñarle a luchar. En la joven fracasa el modelo social patriarcal. No es capaz de enfrentarse a lo radicalmente distinto y salir airosa. La machi no la despoja de su voluntad, ella ya no tenía voluntad. El hombre sale librado, sin embargo él es malvado, él engañó a la niña. Y la familia de la niña también es malvada, pues no les importó que sufriera ¿Qué hicieron? La escondieron en el campo para que pasara la pena y quizás su embarazo. Importa destacar que el hombre era un hombre de letras, civilizado, cuyas palabras no son de harina. Te puedo decir, hermano, que lo que aquí se ve, es que una vez más el occidental culpa al otro de su propia tragedia. La machi es el chivo expiatorio.

\section{Referencias}

Benjamin, W. (2015). Juicios a las brujas y otras catástrofes. Santiago: Hueders.

Brunet, M. (1962). La machi de Hualqui. Otros cuentos. Obras completas de Marta Brunet (pp. 256-264). Santiago: Zig-Zag.

. (1962). Ojo feroz. Otros cuentos. Obras completas de Marta Brunet (pp. 245-256). Santiago: Zig-Zag.

Deleuze, G. y Guattari, F. (1996). Mil mesetas. Barcelona: Pre-Textos.

RAE. (2014). Diccionario de la Real Academia Española. Madrid: Espasa

Foucault, M. (1997). El pensamiento del afuera. Valencia: Pre-Textos.

Ginzburg, C. (1991). Historia nocturna. Un desciframiento del Aquelarre. Madrid: Muchnik Ed.

Paz, O. (2006). El arco y la lira. México DF: Fondo de Cultura Económica. 